DEPARTAMENTO DE RADIODIAGNOSTICO E FISIOTERAPIA

Diretor: Prof. Dr. Honorato Faustino Junior

\title{
COLECISTOGRAFIA NO CÃO
}

(CHOLECYSTOGRAPHY IN DOG)

\author{
Maurício Killner \\ Assistente Técnico \\ 1 estampa (4 figuras)
}

O estudo dos processos semiológicos da exploração das vias biliares tem, nos últimos anos, em medicina humana, adquirido grande desenvolvimento. Infelizmente, pela dificuldade semiológica e de outros processos coadjuvantes desta, a exploração das vias biliares em medicina veterinária tem sido quase nula. Daí a razão dêste trabalho, ou seja, da colecistografia no cão.

Segundo MAREK, "são raros os verdadeiros cálculos hiliares, são freqüentes os precipitados grumosos inócuos. Vêzes há em que encontramos verdadeiros cálculos biliares sem transtôrno da saúde, outras vêzes com transtornos digestivos vagos: diarréia, constipaçāo, enfraquecimento. Na oclusão das vias biliares, cólicas por litíase biliar, seguidas por icterícia, tumefação do fígado, febre e morte por esgotamento, auto-intoxicação hepática ou peritonite por perfuraçāo".

Como achado de necroscopia a litíase não é tão rara. Assim é que vários sāo os autores que os têm encontrado, como: Schlottauer-Stalker, Schlottauer, Millar e Hubbar.

Depois dos estudos de Graham e Cole, em 1924, demonstrando a possibilidade de se fazer passar sais de halogênios pelas vias biliares, grande foi o desenvolvimento dos estudos daquelas vias em medicina humana.

De início aquêles autores trabalharam com tetra-clorofenolftaleína, depois com tetra-bromofoneolftaleína e, finalmente, com tetra-iodofenolftaleína de sódio, substâncias muito opacas ao raio $\mathrm{X}$.

Em 1925, Graham, Cole e Copher acharam que os resultados obtidos com o tetra-iodofenolftaleína eram melhores que aquêles obtidos com o tetra-bromo, deviởo, não sòmente às diferenças dos pêsos atômicos daquelas duas substâncias, como tambérn à maior percentagem de halogênio do composto iodado.

A exploração radiológica da vesícula com contraste é conhecida por colecistografia, e graças a ela novos horizontes se abriram para o conhecimento da fisiologia e patologia da vesícula biliar. Baseia-se no princípio de que delerminados compostos da fenolftaleína, contendo certos halogenados como iodo ou 
bromo, quando injetados endovenosamente ou administrados por via oral, são eliminados pelo fígado com a bile, concentrando-se na vesícula biliar, tornando-a visível na radiografia. Devido ao radical fenolftaleína, observam-se cerlos fenômenos orgânicos, como náuseas, vômitos, vertigens, trombose, variações do pulso, etc.. Tardiamente pode-se noţr urticária, diarréia, cólicas intestinais, etc.. Graham e CoIE assinalaram também hematúria e albuminúria.

Em vista dêstes fenômenos, vários foram os pesquisadores que se puseram a campo, a fim de encontrar uma fórmula ideal para o contraste sem os inconvenientes do tetra-iodofenolftaleína.

Dohrn e Diedrich, depois de muitas pesquisas, encontraram um preparado satisfatório, --- ácido beta-(hidroxi-4-diiodofenil-3,5)-alfafenil-propiônico, menos tóxico que o tetra-iodofenolftaleina, quer pela via oral, quer pela venosa. Elimina-se ràpidamente pelos rins, o que explica o fato de não ter efeito laxativo.

Para êste trabalho, seguimos as normas preconizadas por MARSHaLl, segundo o qual um bom meio de contraste para a vesícula biliar deve ter as seguintes condições:

1) - o iodo deve estar firmernente combinado com a molécula orgânica, a fim de evitar o iodismo;

2) — a substância deve ser eliminada em quantidade apreciável pelo fígado;

3) - para que haja uma boa concentração por parte da mucosa vesicular, a molécula deve ser bastante grande;

4) - não deve ter efeito laxativo e ser absorvida ràpidamente pela mucosa intestinal.

\section{MATERIAL E METODO}

Material empregado - Foram cães, de raça, sexo e idade variáveis, do ambulatório clínico e os internados na Faculdade de Medicina Veterinária da Universidade de São Paulo. O número de cães foi de 20 , sendo 11 do sexo masculino e 9 do sexo feminino, variando a idade de 2 a 6 anos e o pêso de 10 a 16 quilos.

A substância de contraste foi o ácido beta-(4-hidroxi-3,5-diiodofenil)-alfafenil-propiônico $\left(\mathrm{C}_{15} \mathrm{H}_{13} \mathrm{O}_{3} \mathrm{I}_{2}\right)$, comercialmente conhecido como "Biliselectan" (Schering). E’ um pó branco, inodoro, solúvel em álcool, éter, acetona e nos álcalis, quase insolúvel na água. 0 seu sal sódico é muito solúvel nesta. 
Contém $51,5 \%$ de iodo, firmemente combinado à moléculâ orgânica, tornando a droga assim completamente inócua, no que diz respeito ao iodismo. JunkMANN demonstrou que esta droga é menos tóxica que o tetra-iodofenolftaleína, quer pela via oral, quer pela venosa.

E' completamente absorvida pela mucosa intestinal, transportada ao fígado e excretada com a bile para a vesícula. Elimina-se ràpidamente pelos rins, aproximadamente $50 \%$ nas primeiras 24 horas e, segundo JUNKMANN, $83 \%$ em 72 horas, o que explica, em parte, o fato de não ter ação laxativa.

A substância usada (Biliselectan) é apresentada no comércio em carteiras de 6 comprimidos de $0,5 \mathrm{~g}$ cada um, perfazendo um total de $3 \mathrm{~g}$.

Experiências efetuadas a fim de se averiguar a dose ótima levaram-nos à conclusão de que o ideal é de 4 comprimidos, como se poderá verificar no quadro dos resultados.

Em medicina humana, vários são os métodos empregados para a administração da droga, como sejam:

1) - Método da dose simples - após refeição leve, sem gordura, administram-se os comprimidos de 5 em 5 minutos, deglutindo-os inteiros ou desfeitos em água;

2) - método das doses fracionadas - às 12 horas dá-se metade da dose, e o restante à noite, como no método anterior;

3) - método da dose dupla - após o almôço, dá-se uma dose total da substância. Ficar sem alimentação até à noite, e depois dar nova dose total.

Para o nosso caso, preferimos o seguinte: após jejum de 24 horas, administramos ao animal os comprimidos inteiros ou desfeitos em água, com intervalos de 5 minutos.

Preferimos 24 horas de jejum, para evitar a lavagem intestinal preconizada em medicina humana.

Antes da administração da droga, tirou-se uma radiografia simples do animal. A seguir, foram tiradas chapas radiográficas de hora em hora, até a visualização completa da imagem vesicular. Os melhores resultados foram obtidos com as radiografias tiradas de 12 a 14 horas após a administração da substância de contraste. (Figs. 1 e 3 ).

Uma vez visualizada a vesícula biliar, o animal era submetido à prova de "Boyden", isto é, independente do talhe do animal, administravam-se 2 gêmas de ovo. 30 a 40 minutos após, em nova radiografia, anotava-se a forma e o volume da vesícula, permitindo assim avaliar a atividade funcional do órgão. (Figs. 2 e 4). 


\section{RESULTADOS}

Referimo-nos aos resultados no quadro abaixo:

\begin{tabular}{|c|c|c|c|c|c|c|c|c|c|}
\hline $\begin{array}{l}\text { ㅇ̆ㅁ } \\
\text { 号 } \\
\text { 乙 }\end{array}$ & $\begin{array}{l}\text { 宽 } \\
\text { 营 } \\
\end{array}$ & 离 & 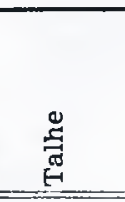 & 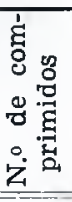 & 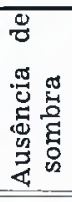 & 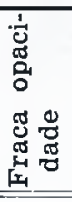 & 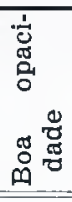 & 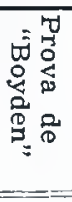 & Observações \\
\hline $\begin{array}{r}1 \\
2 \\
3 \\
4 \\
5 \\
6 \\
7 \\
8 \\
9 \\
10 \\
11 \\
12 \\
13 \\
14 \\
15 \\
16 \\
17 \\
18 \\
19 \\
20\end{array}$ & $\begin{array}{r}3 \\
3 \\
4 \\
4 \\
2 \\
4 \\
5 \\
4 \\
3,5 \\
2,5 \\
6 \\
3 \\
4 \\
3 \\
5 \\
6 \\
4 \\
2 \\
3 \\
2\end{array}$ & $\begin{array}{c}M \\
F \\
F \\
M \\
F \\
M \\
F \\
M \\
M \\
M \\
F \\
F \\
F \\
M \\
M \\
M \\
M \\
F \\
M \\
F\end{array}$ & $\begin{array}{c}\text { médio } \\
\text { pequeno } \\
\text { médio } \\
\text { grande } \\
\text { médio } \\
\text { médio } \\
\text { médio } \\
\text { médio } \\
\text { médio } \\
\text { médio } \\
\text { médio } \\
\text { médio } \\
\text { médio } \\
\text { pequeno } \\
\text { médio } \\
\text { médio } \\
\text { pequeno } \\
\text { médio } \\
\text { médio } \\
\text { médio }\end{array}$ & $\begin{array}{r}2 \\
3,5 \\
3.5 \\
4 \\
2 \\
4 \\
5 \\
4 \\
4 \\
4 \\
4 \\
4 \\
2 \\
3,5 \\
4.5 \\
4 \\
2 \\
4 \\
\varepsilon \\
4\end{array}$ & + & + & $\begin{array}{l}+ \\
+ \\
+ \\
+ \\
+ \\
+ \\
+ \\
+ \\
+ \\
+ \\
+ \\
+ \\
+ \\
+ \\
+ \\
+ \\
+\end{array}$ & $\begin{array}{l}+ \\
+ \\
+ \\
+ \\
+ \\
+ \\
+ \\
+ \\
+ \\
+ \\
+ \\
+ \\
+ \\
+ \\
+ \\
+ \\
+ \\
+ \\
+\end{array}$ & $\begin{array}{l}\text { Colecistite catarro } \\
\text { hemorrágica }\end{array}$ \\
\hline
\end{tabular}

Nota: As radiografias foram tiradas nas seguintes posições: em perfil direito e dorso-ventral.

\section{DISCUSS $\tilde{A} O$}

Foram feitas 20 colecistografias em cães, assim divididos: quanto ao sexo 11 machos e 9 fêmeas; quanto à idade $-3 \mathrm{com} 2$ anos, 1 com 2,5 anos, 5 com 3 anos, 1 com 3,5 anos, 6 com 4 anos, 2 com 5 anos e 2 com 6 anos. quanto ao talhe - 3 de talhe pequeno, 16 de talhe médio e 1 de talhe grande.

Podemos dividir os resultados obtidos em 3 grupos, a saber:

1. grupo) - em que houve ausência da sombra vesicular ( 1 caso);

$2 .^{\circ}$ grupo) - fraca opacidade da mesma (4 casos);

3. grupo) - boa opacidade (15 casos).

No único caso em que houve ausência da sombra vesicular, foi verificada pela necroscopia uma colecistite catarro hemorrágica.

No segundo grupo, o de fraca opacidade, parece ter sido devida a uma pequena dose de substância de contraste administrada ( 2 comprimidos), uma vez que a necroscopia nada revelou, quer no fígado, quer nos ductos biliares. 
O terceiro grupo parece confirmar ainda mais o que ficou dito para o segundo grupo, pois dando-se maior quantidade da droga, nota-se bem a densidade da sombra vesicular.

Nas diferentes doses da substância de contraste administrada, não se constatou.a presença de distúrbios gastro-intestinais, ou outra qualquer perturbação orgânica, nos animais de experiência.

\section{RESUMO E CONCLUSOES}

0 autor, inicialmente, se reporta à dificuldade semiológica em explorar as vias biliares do cão, e propôe para a mesma um método indireto, ou seja. o da colecistografia com contraste, administrado pela via oral, a exemplo do que se tem feito no homem.

As experiências foram efetuadas em um lote de 20 cães, de raça, sexo e idade variáveis.

A substância de contraste usada foi o ácido beta-(4-hidroxi-3,5-diiodofenil). alfafenil-propiônico $\left(\mathrm{C}_{15} \mathrm{H}_{13} \mathrm{O}_{3} \mathrm{I}_{2}\right)$, comercialmente conhecido por Biliselectan.

Para a prova funcional da vesícula, ou seja, a prova de "Boyden", foram usadas 2 gêmas de ovo.

Em seguida, apresenta e discute os resultados, tirando as conclusões seguintes:

1) - E' possível rotineiramente fazer-se a colecistografia em cães.

2) - 0 ácido beta-(4-hidroxi-3,5-diiodofenil)-alfafenil-propiônico (Biliselectan) é uma substância que permite efetuar uma colecistografia em cães, quando administrado pela via oral, dando-nos uma boa sombra vesicular.

3) - A dose ideal da substância de contraste foi de 4 comprimidos.

4) - A substância de contrasté não é tóxica, quando usada nas doses preconizadas.

5) - A visualização da vesícula é completada pela prova do seu esvaziamento, - próva de "Boyden", — subsídio valioso para o diagnóstico das alteraçōes funcionais da vesícula.

6) - 0 primeiro exame radiográfico deve ser realizado de 12 a 14 horas após a ingestão dos comprimidos de contraste.

7) - Em um único caso, no qual não houve visualização da imagem vesicular, foi constatada pela necroscopia uma colecistite catarro hemorrágica.

\section{SUMMARY AND CONCLUSIONS}

The author begins to point out semiological difficulties of exploring the bile ducts of $\operatorname{dog}_{s}$ and proposes for it an indirect method: cholecystography by means 
of a contrast substance administered orally, the same way as performed in man. Experiments were carried out in a batch of 20 dogs of variable lived, sex and age.

The contrast substance used was $\beta$-(4-hydroxy-3,5-diiodophenyl)-phenyl-propionic acid $\left(\mathrm{C}_{15} \mathrm{H}_{13} \mathrm{O}_{3} \mathrm{I}_{2}\right)$, commercially known as Biliselectan.

For the gallbladder function test according to "Boyden" 2 egg yolks were used. He follows by presenting and discussing his results, and finally comes to the following conclusions:

1) - It is possible to perform cholecystography in dogs as a routine.

2) - The $\beta$-(4-hydroxy-3,5-diiodophenyl)-phenyl-propionic acid is a substance which permits cholecystography in dogs when administered by mouth, giving a good vesicular shadow.

3) - The ideal dose of contrast substance were 4 tablets.

4) - The contrast substance is not toxic when given in the specified doses.

5) - The visualization of the gallbladder is completed by the test of its emptying - the Boyden test - a valuable aid in the diagnosis of functional modifications of the gallbladder.

6) - The first radiographic examination should be made 12-14 hours after the ingestion of the contrast tablets.

7) - In one case only in which there was no visualization of the gallbladder, necroscopy revealed a catarrhal hemorrhagic cholecystitis.

\section{BIBLIOGRAFIA}

Dohre - Diedrich "cit." Cabelo Campos, J. M. - Bomptm Pontre, W. - Valor do exame colecistográfico por via oral. Rev. Med. Cir., S. Paulo, f(2):1-2

Graham, E. A. - Cole, W. H. - 1924 - Roentgnologic examination of the gall-bladder. J. A. M. A., 82:613-2

Gramam, E. A. - Cole, W. - Cophen, G. H. - 1925 - Cholecystography (the use of sodium tetraido-phenolphtalein). J. A. M. A., 82:1175-7

Jonkmann, K. - 1941 - Perorale Cholecystographic mit Biliselectan. Klin. Wehnschr., 20:125-8

MareK, J. - 1947 - Tratado de diagnóstico clínico de las enfermedades internas de los animales domésticos: 361. Trad. 3." ed. al. Barcelona, Ed. Labor S.A.

Marshald, W. - 1943 - Some observations on Priodax-new contrast medium for the visualization of the gall-bladder. Am. Jour Roentg. Radth., 50:688-2

Millar, J. A. S. - Hubbar, D. W. - 1946 - Gallstones in a dog. J. A. V. M. A., 108: 160

Schlotthauer, C. F. - Stalker, L. K. - 1936 - Cholelithiasis in dogs. J. A. V. M. A., 41:758-61

Schlotthauer, C. F. - 1945 - Gallstones in dogs. North Am. Vet, 26(6):349-51 
M. Killner - Colecistografia no cão

Estampa 1
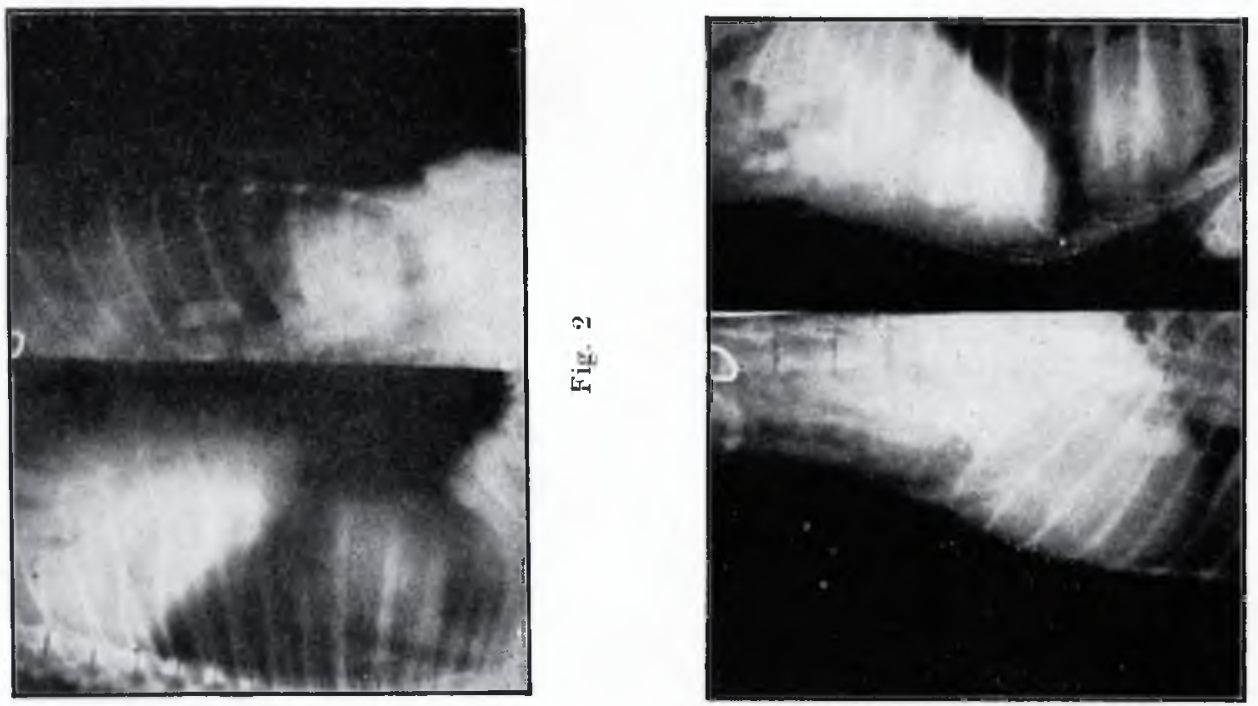

$\vec{i}$
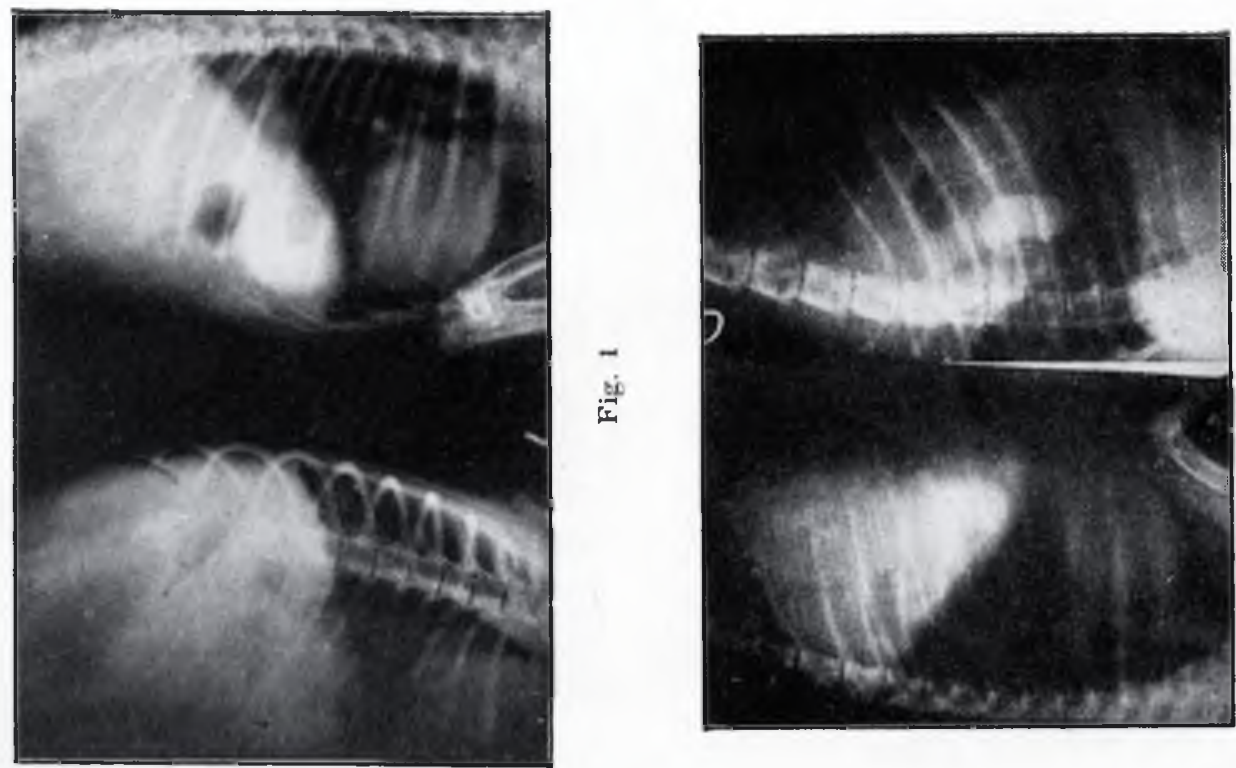

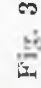

